Orbis Tertius, vol. XXVI, nº 34, e215, noviembre 2021 - abril 2022. ISSN 1851-7811

Universidad Nacional de La Plata

Facultad de Humanidades y Ciencias de la Educación

Centro de Estudios de Teoría y Crítica Literaria

\title{
Una generación de cronistas indígenas novohispanos
}

\section{A Generation of New Spanish Indigenous Chroniclers}

Clementina Battcock cbattcock@yahoo.com.ar

Dirección de Estudios Históricos. Instituto Nacional de Antropología e Historia, Argentina

Recepción: 15 Abril 2021

Aprobación: 08 Agosto 2021

Publicación: 01 Noviembre 2021

Cita sugerida: Battcock, C. (2021). Una generación de cronistas indígenas novohispanos. Orbis Tertius, 26(34), e215. https://doi.org/10.24215/18517811e215

\begin{abstract}
Resumen: El presente artículo ofrece un panorama sobre las crónicas de tradición indígena, en particular las escritas por Hernando Alvarado Tezózomoc, Domingo Francisco de San Antón Muñón Chimalpahin Cuauhtlehuanitzin y Fernando de Alva Ixtlilxóchitl, así como las principales características de la producción historiografía de estos autores. De igual forma, se abordan las diferentes temáticas registradas en las crónicas que brindan un muestrario de la sociedad indígena novohispana del siglo XVI y que ofrecen un amplio abanico de posibilidades para comprender la realidad establecida posterior a la Conquista de México.
\end{abstract}

Palabras clave: Tezózomoc, Chimalpahin, Ixtlilxóchitl, Crónicas, Tradición Indígena.

\begin{abstract}
This paper offers an overview of those chronicles of Indigenous tradition, particularly those written by Hernando Alvarado Tezózomoc, Domingo Francisco de San Antón Muñón Chimalpahin Cuauhtlehuanitzin and Fernando de Alva Ixtlilxóchitl, as well as the main features of these authors' historiographic production. In the same way, the different topics recorded in the chronicles will be studied, showing how they depict New Spain's Indigenous society in the sixteenth century, which helps to understand the reality established after the Spanish Conquest of Mexico.
\end{abstract}

Keywords: Tezózomoc, Chimalpahin, Ixtlilxóchitl, Chronicles, Indigenous Tradition.

Lo único que podemos decir con seguridad es que sólo en parte se nos recordará por lo que consideramos importante de nosotros mismos, o a partir de lo que escogemos para dejar en los documentos o artefactos que nos sobreviven. Los futuros historiadores tendrán que elegir qué hacer con esas cosas: son ellos quienes impondrán significados, así como hoy somos nosotros los que estudiamos el pasado, no quienes vivieron en él.

John Lewis Gaddis, El paisaje de la historia. Cómo los historiadores representan el pasado

La caída y toma de Tenochtitlan en 1521 no solo removió los cimientos de los viejos teocallis, también los de la vida misma de los pueblos mesoamericanos. Desde entonces nada fue igual. Los cambios empezaron de inmediato y, si la antigua nobleza indígena retuvo durante algunos años sus privilegios, para la década de 1560, bajo el reinado de Felipe II, vio disminuir su poder y sus prerrogativas. 
La presencia de los europeos y, en especial, la imposición de nuevas formas culturales, trajo como consecuencia obligada que otras maneras de registrar el pasado irrumpieran en el universo de las historias producidas y trasmitidas entre los indígenas novohispanos. Es irrefutable que en las historias por ellos escritas durante esa segunda mitad del siglo se perciban con claridad esquemas de explicación histórica que corresponden a la tradición europea, en torno a los cuales fue ordenada información de gran riqueza proveniente de las fuentes de la más pura estirpe prehispánica. Así se observa en el contenido de códices pictográficos, en el de los códices glosados e incluso en la información trasmitida a través de la oralidad, es decir, los testimonios que habían recibido los cronistas de boca de sus parientes y mayores, quienes formaban parte de la antigua nobleza y habían sido testigos de los hechos que narraban (Romero Galván, 2003; 2007).

Escritas entre los últimos años del siglo XVI y los primeros lustros del siglo XVII, han llegado hasta nosotros las obras de algunos historiadores indígenas novohispanos: Hernando Alvarado Tezózomoc, Domingo Francisco de San Antón Muñón Chimalpahin Cuauhtlehuanitzin y Fernando de Alva Ixtlilxóchitl. Sus producciones constituyen fuentes de gran importancia tanto para el conocimiento del pasado prehispánico de la Cuenca de México como para el de la realidad novohispana del momento.

Estos tres personajes tuvieron en común varios rasgos característicos que permiten agruparlos en una misma categoría de análisis, al tiempo que pueden establecerse diferencias y similitudes entre ellos. En primer lugar, los tres descendían de las antiguas noblezas de sus respectivos lugares de origen. Alvarado Tezozómoc provenía directamente de los antiguos gobernantes de México-Tenochtitlan, Chimalpahin descendía de los señores de Chalco-Amaquemecan y Alva Ixtlilxóchitl estaba vinculado con la antigua casa reinante acolhua en Texcoco. Es cierto que Hernando Alvarado Tezozómoc era bastante mayor que los otros dos, y sin embargo, a la vista de sus afinidades, es posible considerarlos en bloque como una generación de cronistas indígenas novohispanos, con intereses y perspectivas semejantes. Su linaje encumbrado implica que compartían intereses e inquietudes, en especial relacionados con ese nuevo orden en el que estaban inmersos y que, a fines del siglo XVI, se ofrecía inestable y movedizo, en particular para individuos de noble cuna como ellos.

\section{TEzozómoc Y SUS BELICOSOS MEXICAS}

En torno a 1598, Hernando Alvarado Tezozómoc escribió su Crónica mexicana ${ }^{1}$ Compuesta por 110 o 112 capítulos (Alvarado Tezozómoc, 1987; 1997), se organiza en tres partes de distinta extensión. ${ }^{2}$ La primera, formada solo por tres capítulos, refiere la salida de los mexicas de Aztlan-Chicomoztoc, su migración y su llegada al islote en medio de los lagos de la Cuenca de México donde fundaron su ciudad. La segunda, que comienza en el capítulo cuatro y concluye en el nueve, da cuenta de los primeros años de vida de la nueva ciudad hasta el tiempo en que se sacudieron de la dominación de los azcapotzalcas, a quienes hasta entonces debían pagar tributos onerosos. La última parte, la más extensa en cuanto al número de sus capítulos, es un rico relato de la historia de México-Tenochtitlan, entidad libre, miembro de la triple alianza que, surgida de la guerra contra los tepanecas de Azcapotzalco, quedó constituida también por los señoríos de Texcoco y Tlacopan.

Puede decirse que la espina dorsal del argumento es una sucesión de guerras victoriosas que permitieron a los mexicas alcanzar la hegemonía. Y esto es perceptible a tal grado que el contenido de la Crónica mexicana bien puede resumirse en una frase: los mexicas hacen la guerra para obtener honores y riquezas. Esta sola proposición es el tronco de una inmensa fronda discursiva por mucho que, frecuentemente, se lo oculte o disimule. Así son las guerras que figuran en la derrota ante los tarascos:

Mira la muerte que con semejante guerra se les siguió aquí en Chapultepec a los mexicanos y en Acolco ¿no fue preso y muerto nuestro rey que fue Huitzilihuitl el viejo y con él mucho número de preciados mexicanos, nuestros abuelos, padres y hermanos nuestros salieron valerosos y victoriosos (...). Ahora son nuestros vasallos y tributarios. Y así hemos de ir adelante, 
que la mucha porfía vence y les causa tantos recuentos, si no miradlo por los chalcas, que al cabo de trece años los sujetó el imperio mexicano (Alvarado Tezozómoc, 1987, p. 426).

La guerra es el núcleo del pensamiento y tal empresa es natural a los mexicas. Desde el principio mismo de la obra el tono es bélico: Huitzilopochtli, dios tutelar, se refiere a sí mismo como aquel cuyo cargo es hacer la guerra, y así ordena a su pueblo que la emprenda, lo mismo si se trata de conquistas, de campañas punitivas o, más tarde, de la llamada "guerra florida" destinada a obtener cautivos para el sacrificio. La intensidad y frecuencia de estas acciones de armas y el consiguiente sojuzgamiento de diversos pueblos, que mucho redituaban materialmente a los mexicas, explica que, al arribo de los españoles en 1519, México-Tenochtitlan fuese el centro político y económico más importante de Mesoamérica.

Por otro lado, cabe señalar que el protagonista y sujeto exclusivo del relato es el grupo de los mexicas, lo que en modo alguno incluye a todos los habitantes de la ciudad tenochca, sino únicamente a los pipiltin o nobles. Y no es que el pueblo o los macehualtin estén ausentes; ciertamente forman parte de la escenografía, pero su aparición es incidental, o, para decirlo con más precisión, intervienen para expresarse en relación con los actos o papeles de los protagonistas, los tlatoque o señores. En este ejemplo aparecen los indígenas derrotados por las huestes tenochcas dando "alaridos de obediencia" al "Rey" Tizoc:

Llegaron los viejos y hecha la humillación al rey y a los capitanes, les hicieron un largo parlamento de mucha autoridad, que por su complejidad no la explico aquí (...) daban alaridos, Motenhuitqui, que así hacían los moros de Granada, dando alaridos o silbos (Alvarado Tezozómoc, 1987, p. 445).

La prolija descripción de la gloria de un pasado guerrero y del señorío de sus mayores le permite a Alvarado Tezozómoc dejar constancia del influjo y poder de sus ancestros y también hacer una sutil denuncia, una melancólica elegía por aquel mundo grandioso que ya no habría de regresar jamás:

Son estos los principales valerosos mexicanos y los fundadores de México Tenochtitlan y los primeros capitanes y conquistadores que ganaron y ensancharon esta gran república y corte mexicana, y las tierras y pueblos que pusieron en sujeción y cabeza de México Tenochtitlan; que estos tales principales por ellos ha sido y es cabeza de México Tenochtitlan y su grandeza y señorío que hoy es (Alvarado Tezozómoc, 1987, p. 249).

Hasta ahora no se ha dicho aquí que la Crónica mexicana fue escrita en español. Sin embargo, quien la lee y examina con atención advierte de inmediato que el léxico y la sintaxis son realmente peculiares y no coinciden del todo con las formas propias del castellano del siglo XVI. La crítica especializada ha señalado que esto pone en evidencia que el autor traducía directamente de un texto en náhuatl y que su versión española era un calco de las formas gramaticales y sintácticas de aquella lengua (Romero Galván, 2003). Este rasgo de la Crónica mexicana, así como su gran parecido con el primer volumen de la Historia de las Indias de Nueva España e Islas de la Tierra Firme (Durán, 1995), obra contemporánea del dominico fray Diego Durán, la vinculan de manera directa con uno de los problemas historiográficos más interesantes de la historia de la historiografía novohispana. ${ }^{3}$ Se trata de aquello que se ha denominado Crónica X (Chavero, 1987; Bernal, 1947; Colston, 1973; Tena, 1997; Graham, 1998; Romero Galván, 2003; Peperstraete, 2007; Battcock, 2015).

Unas palabras a este respecto: en el siglo XIX, el erudito Alfredo Chavero había hecho notar la similitud entre la obra de Tezozómoc y la de Durán, y también sugería la posible existencia de una crónica anterior, fuente de ambas. Sin embargo, es en 1945 cuando, en una conferencia dictada en la Facultad de Filosofía y Letras de la UNAM, Robert Barlow perfiló con claridad la hipótesis de la Crónica X. Según él, esta sería una "relación" original en lengua náhuatl escrita por un noble de origen mexica, conocedor del pasado del señorío de sus mayores. Sea tal cosa cierta o no, lo más interesante de la propuesta de Barlow fue que atrajo la mirada sobre la perspectiva de plantear verdaderas redes de filiación entre varias obras historiográficas, pues en torno a las crónicas escritas por Hernando Alvarado Tezozómoc y fray Diego Durán existe un grupo perfectamente bien delineado de obras vinculadas por lazos de parentesco. Y este lo forman el Códice Ramírez (Chavero, 1987), el libro VII de la Historia natural de las Indias del jesuita José de Acosta (2008) y el Manuscrito Tovar (Tovar, ca. 1585), historias ligadas de forma directa con la obra de Durán, que bien podría considerarse la 
crónica madre de todas ellas. El texto de Tezozómoc sería hermano del de Durán, y ambos resultarían hijos legítimos de la Crónica $X$, una obra que, acaso, jamás conoceremos (Battcock, en prensa).

\section{LA SÍNTESIS DE DOS MUNDOS EN CHIMALPAHIN}

Vastedad es la palabra que define la obra de Domingo Francisco de San Antón Muñón Chimalpahin Cuauhtlehuanitzin. ${ }^{4}$ Esta consta de ocho relaciones y del "Memorial breve acerca de la fundación de la ciudad de Culhuacan", que conforman las llamadas Diferentes historias originales, además de un Diario. ${ }^{5}$ A decir verdad las obras de este autor chalca sufrieron el infortunio de acabar siendo dispersadas. La mayor parte de sus trabajos se conservan hoy en el Fondo de Manuscritos Mexicanos de la Biblioteca Nacional de Francia; otra porción menor se resguarda, desde 2014, en la Biblioteca Nacional de Antropología e Historia de México. ${ }^{6}$

El cronista abrevó en fuentes muy variadas para la elaboración de sus textos. Por la somera descripción que ofrece de algunos de ellos, es obvio que tuvo a la vista códices, tanto pictográficos como anotados y transcritos. También recurrió a testimonios orales directos de los nobles ancianos chalcas, y a esta masa informativa se sumó aquella que recabó en textos occidentales. Nótese como ejemplo esta descripción que Chimalpahin recupera de Fray Martín de Valencia, principal de los doce primeros franciscanos, a quien su cristianismo eremita y constante presencia en las cuevas de la región de Amecamecan hizo fuerte entre los indígenas por su asociación con un Tezcatlipoca ataviado con "andrajos sucios y pies agrietados" (Chimalpahin, 1998, p. 185), y que sólo "comía al mediodía (...) mole de guajolote" (p. 195). El resultado natural de la heterogeneidad de sus fuentes es que sus escritos tienen un carácter sumamente peculiar: el de un extraordinario crisol cultural en el que coexisten tradiciones y elementos de origen prehispánico con los de raigambre europea.

Con el nombre de Diferentes historias originales se conoce al extenso manuscrito antes mencionado. Anticipo que, por la diversidad de su temática, y en aras de la claridad y la secuencia, no me ceñiré al orden expositivo de los originales. Su "Primera relación" equivale al libro bíblico del Génesis, pues refiere la creación del mundo, el drama de la caída en pecado del hombre y su expulsión del Paraíso terrenal, amén de otros pasajes. La "Segunda relación" se dedica el advenimiento de Cristo. Estas dos dejan sentados los temas esenciales de la concepción cristiana de la historia: el pecado original y la redención, esto es, la trayectoria humana en la historia de la salvación, cuyo principio y fin es Dios. La "Cuarta relación" da cuenta del poblamiento de América a partir de la hipótesis de que el hombre no es autóctono de este continente, sino que llegó a él proveniente del Viejo mundo. Esta afirmación resultaba indispensable para probar que los amerindios descendían forzosamente de Adán y Eva, y que, en consecuencia, habían sido redimidos por Cristo, lo que, de paso, los inscribía por derecho propio en la historia de la salvación.

La historia de los pueblos del altiplano en los tiempos prehispánicos aparece en el "Memorial breve..." que, por cierto, en las Diferentes historias se incorpora inmediatamente después de la "Segunda relación". Ahí, como cabría esperar, se dan pormenores del poblamiento de la región sur de la Cuenca de México y del surgimiento del señorío de Culhuacan. La "Tercera relación” se dedica al proceso de ocupación de otras regiones y a la historia de los mexicas. En las relaciones quinta, sexta y séptima se trata del devenir de estas regiones y se da cuenta de la sucesión de gobernantes en algunos de los señoríos, así como de las guerras más importantes. Además, en dos de ellas, la sexta y la séptima, aparte de estos asuntos, se tocan aspectos de la historia novohispana relacionada con el mundo indígena. La "Octava relación" es en verdad singular, porque constituye un prolijo informe genealógico del propio autor y un listado de las diversas fuentes de las que se sirvió para la confección de sus relaciones históricas. Además, en distintos pasajes de esta misma octava relación, Chimalpahin da a conocer su propio concepto de la historia. En contra de la creencia común en su época de que la historia era simplemente un relato de lo acontecido en otros tiempos, este cronista asevera 
que tal nombre solo puede dársele al discurso veraz que surge de las indagaciones del pasado y no al mero acaecer de los hechos.

Por su parte el Diario - que muy posiblemente habría formado parte de alguna de las relaciones- es un documento sugerente, pues constituye una colección de efemérides que retratan el día a día de la capital del virreinato. Al leerlo quedan vivas impresiones sobre el peso definitivo de la religiosidad en la existencia cotidiana del novohispano. Quizá uno de los pasajes más conocidos sea su relato de los "embajadores japoneses" que visitaron la Nueva España, del cual a continuación cito un fragmento:

Hoy jueves por la tarde, a 16 del mes de diciembre de 1610 años, cuando sonaban seis campanadas, aquí vienen a acercarse al interior de la ciudad de México, bien pueden ser diecinueve personas del Japón, personas chinas. Un noble señor de ellos los ha traído, embajador en el lugar del señor, del gran gobernante, emperador del Japón, ha venido para hacer la paz con los cristianos, para que nunca guerreen, que siempre tranquilamente vivan, sean estimados, para que puedan entrar los españoles mercaderes, pochtecas, allá al Japón, para que nadie de las gentes de allá se lo impida (Chimalpahin, 2001, p. 132).

Una última nota: hasta fecha muy reciente la obra denominada Crónica Mexicayotl había sido atribuida al cronista Hernando Alvarado Tezozómoc (2015, f. 20). Sin embargo, a principios de la década de 1980 aparecieron en la Biblioteca de la Sociedad Bíblica de Londres tres volúmenes de la colección que en el siglo XVII perteneció a don Carlos Sigüenza y Góngora. Entre otros manuscritos autógrafos de Chimalpahin, uno de tales volúmenes contenía la referida Crónica mexicáyotl. A través del análisis de dicho texto, hoy se ha podido determinar que la mayor parte de esta historia fue, en realidad, obra del cronista chalca, quien, por propia mano, agregó dos fragmentos, uno escrito originalmente por Alvarado Tezozómoc y el otro por un mestizo de nombre Alonso Franco. ${ }^{7}$

\section{Alva IXTILixóchitL: LA CRISTIANDAD EN Texcoco}

Fernando de Alva Ixtlilxóchitl legó a la posteridad cinco obras, todas escritas en español y dedicadas principalmente a referir el pasado prehispánico de Texcoco. ${ }^{8}$ Como en el caso de Chimalpahin, Ixtlilxóchitl echó mano de una amplia gama de fuentes, entre las que cabe destacar, en primer lugar las "pinturas" y "pinturas originales" que tuvo a su alcance y que narraban en pictogramas la historia del antiguo señorío texcocano. No discriminó este cronista los textos de indígenas originarios de otros señoríos de la Cuenca de México, muchos de las cuales formaron parte de colecciones documentales que eran propiedad de los nobles, como fue el caso de aquella que poseyó Alonso Axayácatl. Como en el ejemplo del cronista previo, la base testimonial verbal aportada por ancianos indígenas fue destacada, al igual que lo fue la inclusión de textos y fuentes de la cultura europea, de suerte que también en Alva Ixtlilxóchitl se percibe un esfuerzo por vincular la historia prehispánica con la de Occidente.

La historia que ofrece Ixtlilxóchitl en sus cinco relaciones está concatenada y dispuesta de manera cronológica. Naturalmente, comienza por la creación, episodio en el que está implicado todo el género humano, indígenas incluidos, y cierra con el relato particular de la vida de los señores de Texcoco, señorío del que procedía la familia del autor. En la edición preparada por Edmundo O’Gorman a las Obras completas de Fernando de Alva Ixtlilxóchitl, este historiador propuso el orden de las cinco relaciones después de contrastar el contenido de cada una de ellas:

1. Sumaria relación de todas las cosas que han sucedido en la Nueva España, y de muchas cosas que los tultecas alcanzaron y supieron desde la creación del mundo hasta la venida de los terceros pobladores chichimecas, hasta la venida de los españoles, sacada de la original historia de esta Nueva España. Efectivamente, el contenido parte desde la creación del mundo, el origen de los toltecas y continúa con la llegada del "gran chichimeca Xólotl”, su instauración en la cuenca de México y la vida y obra de sus descendientes. Concluye con la llegada de los españoles y la adhesión de los tetzcocanos a sus filas. 
2. Relación sucinta en forma de memorial de la historia de Nueva España y sus señorios hasta el ingreso de los españoles. En efecto, se trata de una historia resumida de los toltecas y gobernantes chichimecos. Incluye una interesante dedicatoria a uno de los virreyes de la Nueva España, pero no el nombre de dicho personaje.

3. Compendio histórico del reino de Texcoco. En esta historia el cronista inicia directamente con el origen de los grupos chichimecas, continúa escuetamente con los gigantes y toltecas, y se ocupa después de los gobernantes chichimecas. En esta historia proporciona mayor información de la llegada de los españoles y la evangelización y termina con el acta de ayuntamiento de Tetzcoco.

4. Sumaria relación de la historia general de esta Nueva España desde el origen del mundo hasta la era de ahora, colegida y sacada de las historias, pinturas y caracteres de los naturales de ella, y de los cantos antiguos con que la observaron. Contiene en primer lugar una dedicatoria a un ilustre personaje del que solo se saben sus iniciales (V.S.I.), un prólogo al lector y, de manera escueta, el origen tolteca, el arribo chichimeca y sus gobernantes. Describe también los sucesos posteriores a la muerte de Nezahualcóyotl y la guerra con Chalco. La relación parece quedar inconclusa, pues no relata nada sobre la llegada de los españoles.

5. Historia de la nación chichimeca. Se trata de la obra más extensa de Fernando de Alva Ixtlilxóchitl: inicia con la creación del mundo, continúa con la historia tolteca, la historia de los grupos chichimecas de Xólotl y su linaje, y se centra especialmente en Nezahualcóyotl y el después de la Conquista y el apoyo que prestaron a tal empresa los antepasados de Fernando de Alva Ixtlilxóchitl.

En la versión de Alva Ixtlilxóchitl, el pasado indígena precortesiano adquiere pleno sentido al insertarse en el decurso de la historia universal, cristiana y providencialista. Esto se advierte en un intento de vinculación, que llamaríamos sincrónico, de los acontecimientos relevantes de este lado del Atlántico con los acaecidos en el opuesto. Así por ejemplo, al referirse a algún suceso notable en Texcoco, el cronista se toma el trabajo de puntualizar en la época de qué Papa o qué soberano europeo se desarrollaba el hecho en cuestión.

Para este autor quedaba fuera de toda duda y sospecha que el devenir histórico de las Indias, incluso antes del arribo de los españoles, estaba ligado al destino de la salvación del género humano, e incluso que ya había en estas tierras conocimiento o al menos intuición del verdadero y único Dios. El ejemplo más conspicuo nos lo ofrece con Nezahualcóyotl, el más célebre de los gobernantes texcocanos. La pintura que hace Alva Ixtlilxóchitl de este personaje, sabio, virtuoso, justo y clemente, es la de un príncipe cristiano, que parece extraído de los manuales que tan en boga estuvieron en el siglo XVI europeo. Fue Nezahualcóyotl un gran señor, que llegó casi a burlarse de los ídolos, a poner en tela de juicio la existencia de muchos dioses y a repudiar los sacrificios humanos. Esto constituía el preludio, la intuición manifiesta del próximo arribo del evangelio (Battcock y Aguilar, 2016; Romero Galván, 2003).

\section{Palabras finales}

Los tres autores cuyas obras he abordado brevemente constituyen el más sólido eslabón en la cadena de la historiografía novohispana de tradición indígena. Ya se ha apuntado que en sus obras se entretejió la información procedente de dos culturas madre que, habiendo entrado en un complejo y violento "proceso de sincretismo" a raíz de la conquista, comenzaron a dar frutos propios a finales del siglo XVI, motivo por el cual su interés historiográfico, como fuentes para el conocimiento del pasado prehispánico y de la época en el que vivieron sus autores, está fuera de discusión. Estos escritos no son en absoluto resultado de una resistencia cultural frente al dominador, pero tampoco son crónicas que exhiban un conflicto irresuelto entre dos maneras distintas de percibir el mundo. En ellas se amalgama la riqueza informativa de un abanico de fuentes indígenas de origen anterior a la conquista, con los esquemas explicativos y la concepción histórica propios de 
la Europa moderna. Así lo percibimos en Tezozómoc, el mayor de este grupo, quien exalta el mérito guerrero como algo crucial en el pasado mexica, que además no dejaba de ser un galardón altamente valorado en los primeros años de la vida novohispana, es decir, los años de los conquistadores. Así lo advertimos después, en los más jóvenes Chimalpahin e Ixtilixóchitl, que manifiestan la perfecta simbiosis entre el antiguo esplendor indígena y el camino de la redención cristiana.

Se trata pues de historias surgidas en un momento en el que, al menos en el corazón de la Nueva España, ciertos núcleos sociales vivían en el vórtice de una realidad híbrida y cambiante. De ella comenzaba a surgir un espíritu nuevo, que el sabio mexicano Edmundo O'Gorman (1972) denominaba el espiritu novohispano, algo que era propio y absolutamente distintivo de estas regiones que alguna vez se denominaron Anáhuac.

\section{REFERENCIAS}

Acosta, J. (2008). Historia Natural y Moral de las Indias. Madrid: Consejo Superior de Investigaciones Científicas.

Alva Ixtlilxóchitl, F. (1985). Obras históricas. Ciudad de México: Universidad Nacional Autónoma de MéxicoInstituto de Investigaciones Históricas.

Alvarado Tezozomoc, H. (1943). Crónica Mexicana. Ciudad de México: Universidad Nacional Autónoma de México.

Alvarado Tezozomoc, H. (1987). Crónica Mexicana. Ciudad de México: Porrúa.

Alvarado Tezozomoc, H. (1997). Crónica Mexicana. Madrid: Historia 16.

Alvarado Tezozomoc, H. (2015). Crónica Mexicayotl. En Códice Chimalpabin, vol. III, f. 20. México: Instituto Nacional de Antropología e Historia. Recuperado de http://www.codicechimalpahin.inah.gob.mx/

Barlow, R. (1990). La 'Crónica X: versiones coloniales de la historia de los mexica-tenochca. En J. Monjarás-Ruiz y E. Limón y M de la C. Paillés (Eds.), Obras de Robert H. Barlow. Los mexicas y la Triple Alianza, v. 3. (pp. 13-32). Ciudad de México: Instituto Nacional de Antropología, Universidad de las Américas.

Battcock, C. y Aguilar M. (2016). La creación en la memoria oficial mexicana de un modelo de justicia prehispánica: Nezahualcoyotl Acolmiztli. Saga, Revista de Letras, (5), 319 -342.

Battcock, C. (2015). De crónicas y encuentros. Un recorrido por la obra de Alvarado Tezozomoc. En A. Guerrero (Coord.), Dignidad intercultural (pp. 117-129). Ciudad de México: UNAM-CIALC-Bonilla Editores.

Battcock, C. (en prensa). Misterios y encrucijadas de una crónica perdida. En V. Añón, L. El Jaber y M. Benites (Coords.), Modernidad, colonialidad y escritura en América Latina. Tucumán: Universidad Nacional de Tucumán.

Bernal, I. (1947). Los calendarios de Durán. Más confusiones alrededor de la Crónica X. Revista Mexicana de Estudios Antropológicos, 9, 125-134.

Chavero, A. (1987). Códice Ramírez - Durán - Acosta - Tezozómoc. En H. Alvarado Tezozomoc, Crónica mexicana. Edición facsimilar de la de 1878 (pp. 161-167). Ciudad de México: Porrúa.

Chimalpahin Cuauhtlehuanitzin, D. de S. A. M. (1983). Octava relación, obra histórica de Domingo Francisco de San Antón Muñón Chimalpabin Cuaubtlehuanitzin. Ciudad de México: Universidad Nacional Autónoma de México.

Chimalpahin Cuauhtlehuanitzin, D. de S. A. M. (1998). Las Ochos Relaciones y el Memorial de Colhuacan: Domingo Chimalpábin. Ciudad de México: Consejo Nacional para la Cultura y las Artes.

Chimalpahin Cuauhtlehuanitzin, D. de S. A. M. (2001).Diario. Ciudad de México: Consejo Nacional para la Cultura y las Artes.

Colston, S. A. (1973). Fray Diego Duran's historia de las Indias de Nueva España e Islas de la Tierra Firme: a historiographical analysis (Tesis de Doctorado), Philosophy in History. University of California, University Microfilms International, Los Angeles.

Durán, D. (1995). Historia de las Indias de la Nueva España e Islas de la Tierra Firme. Ciudad de México: CONACULTA. 
Graham Classen, A. M. (1998). Dos interpretaciones de la historia de los mexicas: un análisis comparativo de la Crónica mexicana de Hernando Alvarado Tezozómoc y la Historia de las Indias de Nueva España e islas de Tierra Firme de fray Diego Durán (Tesis de Doctorado). Universidad Nacional Autónoma de México, Facultad de Filosofía y Letras, México.

Inoue Okubo, Y. (2009). La visión contemporánea sobre Ixtlilxóchitl y la visión de Ixtlilxóchitl sobre la historia. La experiencia historiográfica (VIII coloquio de análisis historiográfico) (pp. 229-239). Ciudad de México: UNAMIIH.

Kruell, G. (2013). La Crónica mexicáyotl: versiones coloniales de una tradición histórica mexica-tenochca. Estudios de Cultura Náhuatl, 45, 197-232.

O'Gorman, E. (1972). Prólogo. En F. de Alva Ixtlilxóchitl, Nezahualcoyotl Acolmiztli (pp-13-15). México: Gobierno del Estado de México.

Peperstraete, S. (2007). La “Chronique X": Reconstitution et analyse d'une source perdue fondamentale sur la civilisation Aztèque, d'après l'Historia de las Indias de la Nueva España de D. Durán (1581) et la Crónica Mexicana de F. A. Tezozomoc (ca.1598). Oxford: Archeopress.

Romero Galván, J. R. (Coord.). (2003). Historiografía novohispana de tradición indigena. Historiografia mexicana. Vol. I. Ciudad de México: UNAM-IIH.

Romero Galván, J. R. (2007). Memoria, oralidad e historia en dos cronistas nahuas. Estudios de Cultura Nábuatl, 38 , 165-182.

Ruwet, W. (1994). Los manuscritos de la Bible Society: su historia, redescubrimiento y contendido. En Suma y epiloga de toda la descripción de Tlaxcala (pp. 27-40). Tlaxcala: Universidad Autónoma de Tlaxcala, Secretaría de Extensión Universitaria y Difusión Cultural, Centro de Investigaciones y Estudios Superiores en Antropología Social.

Tena, R. (1997). Revisión de la hipótesis sobre la Crónica X. En C. Vega Sosa, S. Rueda Smithers y R. Martinez Baracs (Eds.), Códices y documentos sobre México. Segundo Simposio (pp. 163-178). Ciudad de México: Instituto Nacional de Antropología e Historia, CONACULTA.

Tovar, J. de (ca. 1585). Manuscrito Tovar. Biblioteca Digital Mundial. Washington: Biblioteca Digital Mundial, Biblioteca del Congreso de los Estados Unidos de América. Recuperado de https://www.wdl.org/es/item/675 9/\# $\mathrm{q}=\mathrm{c} \% \mathrm{C} 3 \% \mathrm{~B} 3$ dice+tovar. 


\section{Figuras}

FIGURA 1

Texto y rúbrica de Fernando de Alva Ixtlilxóchitl. Códice Chimalpahin, Tomo I, 187 (v).

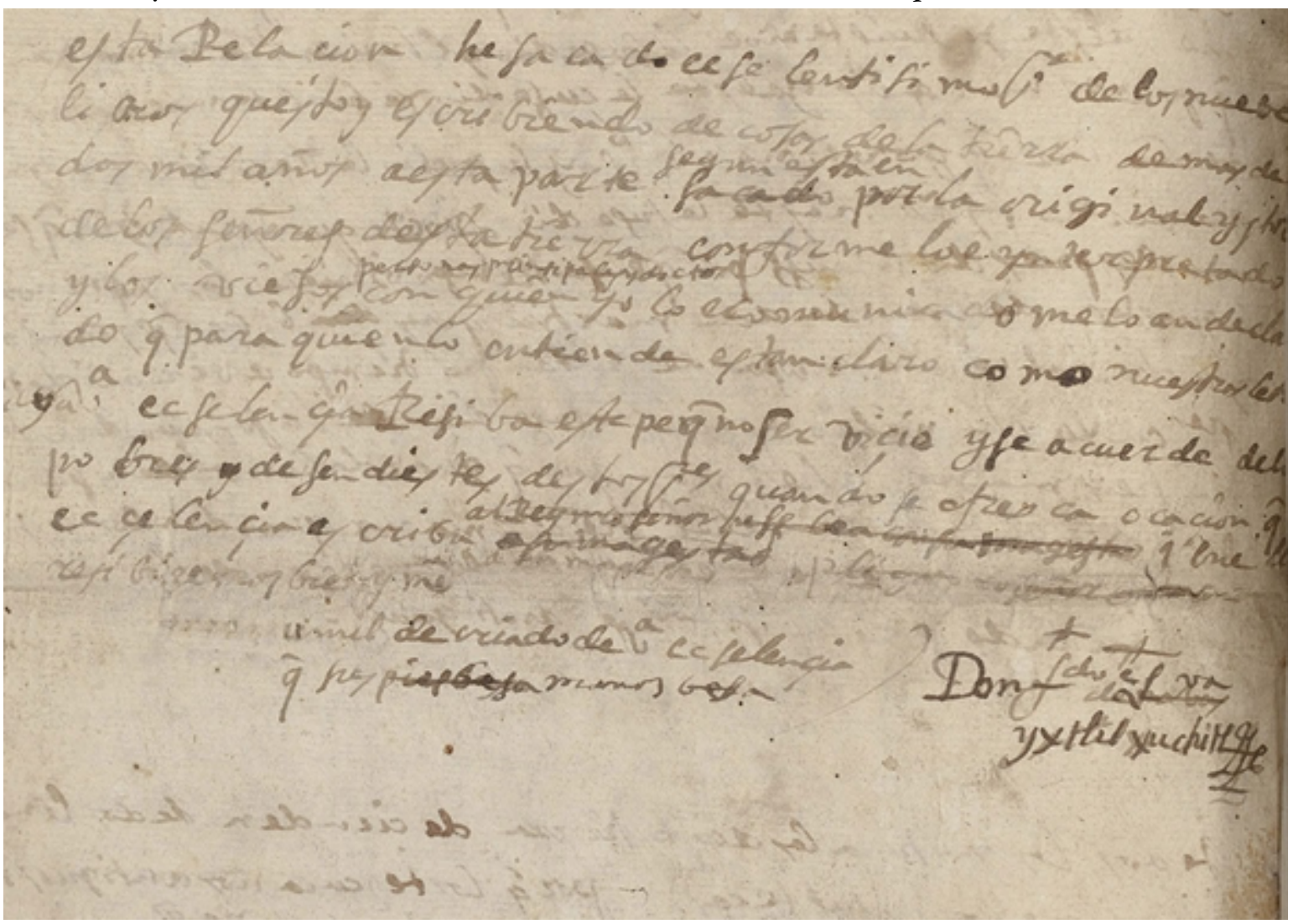


FIGURA 2

"Nican mitohua motenehua ynquenin oacico". Crónica Mexicayotl de Chimalpahin/ Hernando de Alvarado Tezozomoc contenida en Códice Chimalpahin, Tomo III, f. 20 (r).

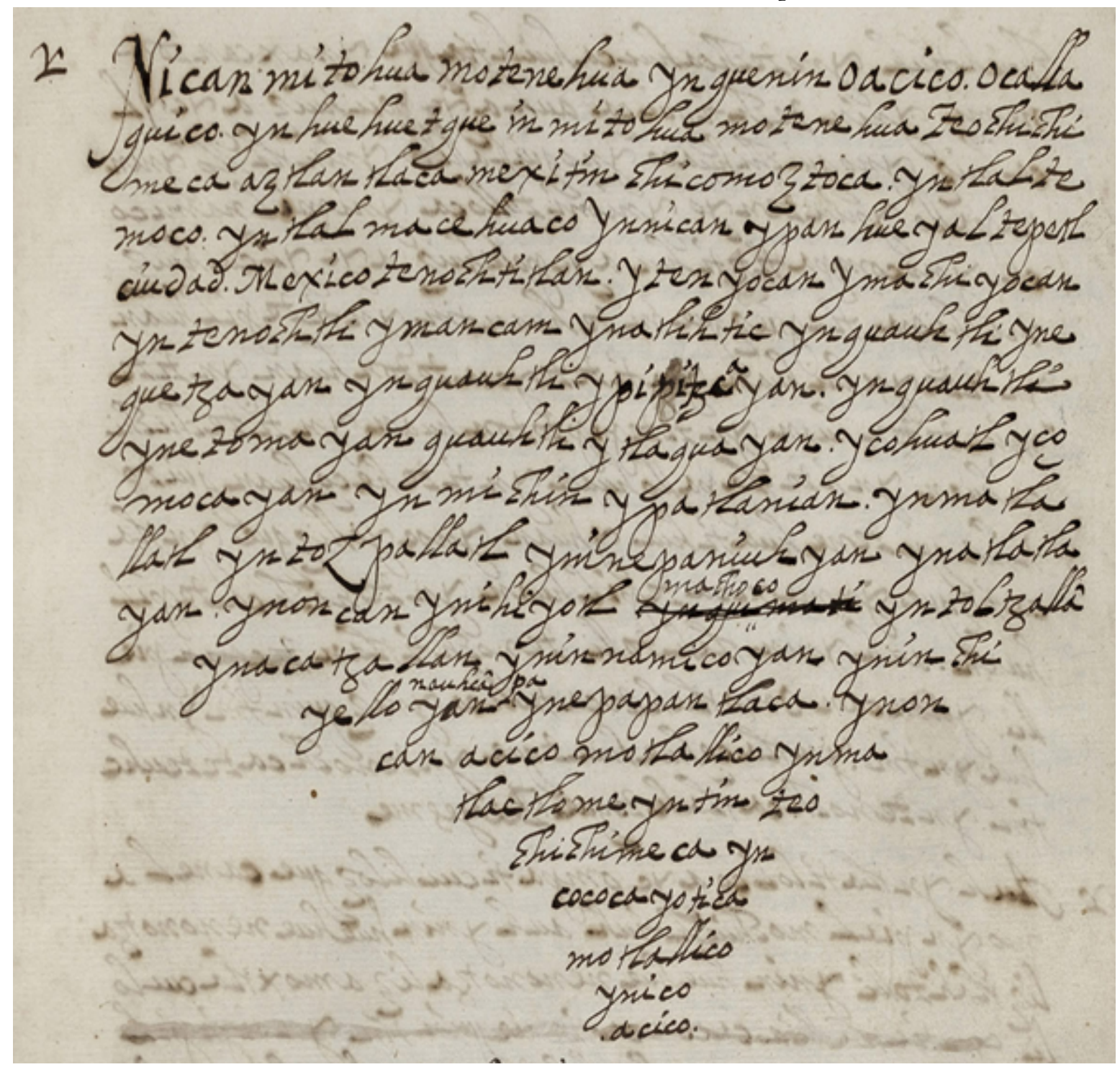

\section{Notas}

1 Hernando Alvarado Tezozómoc nació del matrimonio formado por Francisca de Moctezuma y Diego Alvarado Huanitzin, la primera era hija de Moctezuma Xocoyotzin y el segundo nieto de Axayácatl, es decir que Hernando era pipiltin, noble mexica tenochca. Aunque no se ha logrado precisar su fecha de nacimiento, la propuesta más aceptada gira en torno a los años de 1538 o 1539 (Romero Galván, 2003, p. 86) y se cree -aun en ausencia de prueba documentalque vino al mundo y vivió en la ciudad de México, ya que su padre, Diego Alvarado Huanitzin, fue gobernador de Tenochtitlan hasta el año de su muerte en 1542. Muy probablemente en sus primeros años, Hernando fue educado por sus familiares, quienes lo introdujeron en los antiguos elementos culturales, como la lengua y la historia de su grupo. Es probable que más adelante asistiera a algún convento para ser adoctrinado en la fe católica y para aprender el alfabeto, lo que debió constituir su primer acercamiento a la cultura de los conquistadores. La actividad laboral que se sabe desempeñó Tezozomoc no resultaba de gran lustre ni acorde con su clase, pues era un modesto nahuatlato o intérprete en la Real Audiencia de la Ciudad de México.

2 Entre las ediciones modernas de la Crónica mexicana de Tezozómoc se cuentan la más reciente realizada por Gonzalo Díaz Migoyo y Germán Vázquez Chamorro (1997), publicada en Madrid, España; la editada por Mario Mariscal para la 
colección de la Biblioteca del Estudiante Universitario de la UNAM (1943), y la de mayor consulta que ha sido reeditada en varias ocasiones por la editorial Porrúa en la Ciudad de México (1987), hecha por Manuel Orozco y Berra en 1878.

3 Fray Diego Durán se decidió por hacer una carrera religiosa en la orden de Santo Domingo pasada la mitad del siglo XVI, lugar social en donde se desempeñó como predicador de indios, demostrando gran interés por el pasado y costumbres de estos, expandiendo sus observaciones gracias a la movilidad requerida por su labor misional al territorio de Nueva España, el valle de Cuernavaca y Oaxaca. La Historia de las Indias de la Nueva España e Islas de la Tierra Firme es una obra cuyo contenido es producto de las indagaciones sobre el pasado, costumbres y creencias de los indios. Los resultados plasmados en su obra tuvieron como objetivo en un primer momento, compartir entre sus compañeros de orden el conocimiento por él registrado. Del mismo modo, esta obra fue considerada para ser consultada por un deudo suyo, Juan de Tovar, quien había sido electo para satisfacer el interés de Joseph de Acosta, compañero de oficio, quien estaba recopilando información para su historia natural y moral sobre las Indias.

4 Cuando Chimalpahin nació en la primavera de 1579, su hogar, ubicado en Chalco Amaquemecan, era el reflejo de más de cincuenta años de una intensa y compleja evangelización que se había concretado mediante un consenso corporativo entre las diferentes casas señoriales de los tlayácatl locales, auspiciadas por franciscanos y dominicos. Es probable que Chimalpahin adquiriese parte de su educación en el tecpan familiar de Tzacualtitlan Tenanco, y que también participase en el cuidado, acicalamiento y celebración de festividades relacionadas con la parroquia vecinal consagrada a Santiago. Por su condición de pilli ("persona de la nobleza”), debió acudir de forma rutinaria al convento de Nuestra Señora de la Asunción de Amaquemecan. Tampoco parece improbable plantear que, antes de cumplir los catorce años, pudiese haber llegado a recibir instrucción docente y espiritual en el resto de los conventos que configuraban la malla dominica afincada en la falda de los volcanes Iztaccihuatl y Popocatépetl, como las casas de Chimalhuacan y de Tetela. Hasta donde se sabe, continúan siendo una incógnita los motivos certeros, circunstancias personales y condiciones específicas que promovieron su entrada temprana en 1593 a la ermita de San Antonio Abad, en la parcialidad de San Pablo de México. Sin embargo, es necesario traer a colación aquí que, para esas fechas entre los siglos XVI y XVII, doña Martina y don Nicolás Hernández Tlacaelleltzin -madre e hijo, y descendientes del antiguo y afamado cihuacóatl Tlacaelel- constituían la cabeza visible de una prestigiosa feligresía indígena afincada en los adyacentes barrios tenochcas de Ateponazco y Xolloco Acatla, y que sería adepta y devota del cercano San Antonio Abad. Es probable que la llegada de Chimalpahin a este espacio de la Ciudad de México pueda estar relacionada con las viejas conexiones genealógicas que el linaje del cihuacóatl Tlacaelel de México-Tenochtitlan mantenía con las autoridades de varios tlayácatl de Chalco Amaquemecan, desde la etapa final del periodo Posclásico tardío. Redes parentales que, durante el virreinato temprano, podrían haber facilitado el surgimiento de verdaderos circuitos de desplazamiento de feligreses, que abandonarían en la adolescencia su hogar para instruirse y prestar servicios en los nuevos centros espirituales urbanos.

5 Las ediciones de mayor consulta hechas a los manuscritos de Chimalpahin son las de Rafael Tena (1998), que agrupan las denominadas Ocho relaciones y el memorial de Colhuacan, así como la traducción del Diario de este nahuatlato virreinal, hecha por el mismo investigador (2001). Es debido mencionar el cuidadoso trabajo realizado a la octava relación editada por José Rubén Romero Galván (1983).

6 El 20 de mayo de 2014 la Sociedad Bíblica de Londres y el gobierno del Estado mexicano concretaron un acuerdo en el que se retirarían los 3 volúmenes, denominados Códice Chimalpahin, de la subasta programada para el día 21 del mismo mes por la casa Christiés. Dicha sociedad poseía los documentos desde 1827, y el 18 de agosto del mismo año fueron devueltos a territorio mexicano y puestos bajo custodia de la Biblioteca Nacional de Antropología e Historia del Instituto Nacional de Antropología e Historia, ubicada en el Museo Nacional de Antropología. Sobre la antigua localización e historia de estos manuscritos, véase Ruwet, 1994.

7 Para una síntesis de los planteamientos en torno al estudio de la composición, así como de los cronistas indígenas que intervinieron en esta obra, véase Kruell (2013).

8 Sobre las miradas historiográficas hechas a las obras de Fernando Alva Ixtlilxóchitl, y la concepción propia de Ixtlilxóchitl sobre la historia, véase a Inoue Okubo (2009). La edición más socorrida para la investigación es la realizada por el erudito historiador Edmundo O'Gorman, intitulada Obras históricas y publicada en 2 volúmenes, el primero de los cuales apareció en 1975 y el segundo en 1977. 